\title{
Sobre los municipia del ámbito territorial castellano-manchego
}

\author{
G. Carrasco Serrano *
}

\section{RESUMEN ABSTRACT}

El presente trabajo tiene por objeto fundamental, el análisis de aquellos núcleos que alcanzarian en época romana estatuto municipal dentro del actual ámbito geográfico castellanomanchego. Asi pues, mientras Segobriga, Valeria y Ercavica son considerados municipos augusteos, otros sin embargo como Laminium, Consabura, etc., son de época flavia. $A$ estos núcleos se añaden otros que es probable llegasen a alcanzar condición privilegiada, y de datación más dudosa.
The fundamental goal of this study is the analysis of those centres of the Roman Empire that would be considered municipalities, within the present geographical area of CastillaLa Mancha. While Segobriga, Valeria and Ercavica are considered to be Augustan municipalities, others such as Laminium and Consabura are from the Flavian period. To these centres we may add others that probably acquired privileged status, making it difficult to date them accurately.

Son diversos los núcleos de población que en la actual área geográfica castellano-manchega, llegarian a alcanzar en época romana categoría municipal. Así pues, tanto de Laminium como de Consabura se posee testimonio donde se hace mención explícita (municipium Flavium Laminitanum; munic(ipii) Consaburon(is) ${ }^{1}$ a dicha condición aicanzada.

Laminium es citado por varias fuentes antiguas, como el Itinerario de Antonino al constituir un cruce de caminos (It. Ant., 445, 4: Lamini; 446, 4: Liminio; 446, 8: Laminio), del cual partirian dos vías, una de ellas a

* Universidad de Castilla-La Mancha.

1 CIL, II, 3251-2; CIL, II, 3228; CIL, II, 4211. 
Toletum (It. Ant., 446, 4-7), y otra a Caesaraugusta (It. Ant., 496, 8-448, 1). También es mencionado por el Anónimo de Rávena (313, 17: Lamini), y por Ptolomeo (II, 6, 56: $\Lambda \alpha \mu$ iviov, $\left.\iota^{\prime \prime} \gamma^{\prime \prime} \lambda \theta L^{\prime \prime} \gamma^{\prime \prime} \imath \beta^{\prime}\right){ }^{2}$; por su parte Plinio (N.h., III, 6) pone precisamente el origen del río Anas en el ager Laminitanus (ortus hoc in Laminitano agro Citerioris Hispaniae...) ${ }^{3}$. Asimismo Plinio (N.h., III, 25) en la relación de populi pertenecientes al conventus Carthaginensis incluye a los laminitani entre los estipendiarios. De todos modos epigráficamente puede constatarse que la ciudad alcanzaría status municipal ${ }^{4}$ bajo los Flavios. A pesar de haberse situado frecuentemente en Fuenllana ${ }^{5}$, sin embargo últimamente su ubicación en la localidad de Alhambra es la aceptada ${ }^{6}$.

Por lo que respecta a Consabura, en Ps. Frontino, IV, 5, 19 (Hispani Consabrae obsessi eadem omnia passi sunt nec oppidum Hirtuleio tradiderunt)

2 Aoutviov en el codex Parisiensis Supplem. 119, Parisiensis, 1402, Parisiensis Coislin 337, Vindobonensis, 1, Oxoniensis Seldanus, II, 46, Venetus, 383, Venetus, 516, Mediolanensis, D, 527, Vaticanus, 191, Vatic. Palatinus, 314, Vatic. Palatinus, 388, Florentinus Abbatiae, 2380 , Barberinus, Florentinus Laurentianus, XXVIII, 9, idem, XXVIII, 38, idem, XXVIII, 49, y Constantinopolitanus. Variantes de graduación: $L^{\prime \prime} \gamma^{\prime \prime}$ aparece en el Florentinus Laurentianus, XXVIII, 9, idem, XXVIII, 38, idem, XXVIII, 42; i $\gamma$ en el Parisiensis, 1404, idem, 1403, Parisiensis Coislin, 337, Parisiensis, 2423, Oxoniensis Seldanus, II, 46, Mediolanensis, D, 527, Vatic. Palatinus, 314, Florentinus Laurentianus, XXVIII, 49, y Constantinopolitanus. La graduación $\lambda \theta L^{\prime \prime}$ $\gamma^{\prime \prime} \beta^{\prime \prime}$, se da en el Vaticanus, 191, Florentinus Laurentianus, XXVIII, 9, idem, XXVIII, 38, idem, XXVIII, 42; $\lambda \theta^{\prime} \gamma o^{\prime \prime}$ en el Parisiensis, 1404, idem, 1403, Parisiensis Coislin, 337, Vatic. Palatinus, 314; $\lambda \theta^{\prime} \delta^{\prime \prime}$ en el Athous Vatopedi monasterii. ág. 66 .

Vid., A. SChulten, Geografía y etnografía antiguas de la Península lbérica, II, Madrid, 1963,

${ }_{4} \mathrm{CIL}, \mathrm{II}$, 3228: municipi Laminitani; CIL, II, 3251-2: municipium Flavium Laminitanum. Véase R.K. MCELDERRY, "Vespasian's reconstruction of Spain", JRS, 8, 1918, pág. 74; H. Galsterer, Untersuchungen zum römischen Stadtewesen auf der lberischen Halbinsel, Berlín, 1971, pág. 47 y 71; B. Galsterer-Kroll, "Untersuchungen zu den Beinamen der Städte des Imperium Romanum", en Epigraphische Studien, 9, 1972, pág. 113, n. ${ }^{\circ}$ 188; J.N. BONNEVILLE ET ALII, “Las villes romaines de la Peninsule Iberique", Les Villes dans le monde lberique, Paris, 1982, pág. 16. Muy probablemente, y al igual que en otros núcleos de población, la presencia o vinculación con grupos familiares procedentes de otros puntos, constituirá elemento a tener en cuenta en la promoción de la ciudad, vid. al respecto G. ALFOLDY, Römisches Städtewesen auf der neukastilischen Hochebene. Ein Testfall für die Romanisierung, Heidelberg, 1987, págs. 36-37; J.M. ABASCAL, U. ESPINOSA, La ciudad hispano-romana: privilegio y poder, Logroño, 1989, pág. 72, y 88 nota 63. Por otra parte y en relación a la tribu de esta comunidad y su problemática véase, R. WiEgeLs, Die Tribusinschriften des römischen Hispanien, Berlín, 1985, págs. 152-153; G. ALFOLDY, Römisches Städtewesen..., op. cit., págs. 35-37.

5 Véase por ejemplo, E. Flórez, España Sagrada, V, pág. 22; también entre otros A. SCHULTEN, RE, XII, 1, 1924, col. 562; R.K. MCELDERRY, "Vespasian's...”, art. cit., pág. 74

6 Cf. M. Corchado Soriano, Avance de un estudio geográfico-histórico del Campo de Montiel, Madrid, 1971, pág. 39; G. Alfoldy, Römisches Städtewesen..., op. cit., págs. 33-34; A. TovaR, Iberische Landeskunde. Las tribus y las ciudades de la antigua Hispania. 3, Tarraconensis, BadenBaden, 1989, pág. 180; G. CaraAsco Serrano, "Núcleos de población romanos en la provincia de Ciudad Real», HAnt., XXI, 1997, págs. 302-303; véase no obstante al respecto, la hipótesis de G. ARIAS, ME, 25, 1990, págs. 5-6 
se hace referencia a este núcleo ya con motivo de las operaciones militares llevadas a cabo durante las guerras sertorianas en el año 79 a.C. " También es citado en la vía Item a Liminio Toletum descrita por el Itinerario de Antonino (It. Ant., 446, 6: Consabro), entre Murum y Toletum distante de esta última XLIIII m.p., así como por el Anónimo de Rávena $(313,15)$ con el nombre de Consabron ${ }^{8}$. Plinio en su obra (N.h., III, 25) la cataloga entre las ciudades estipendiarias del conventus Carthaginensis; no obstante, y según el testimonio de la inscripción (CIL, II, 4211) dedicada a $L$. Domitius $M$. fil. Serg. Dentonianus ${ }^{9}$ quien ostenta el cargo, entre otros ${ }^{10}$, de duumviro del municipium de Consabura, queda claramente constatada su categoría municipal ${ }^{11}$ alcanzada. El hecho, por otra parte, de que Domitius Dentonianus perteneciera a la tribu Sergia ${ }^{12}$, ha planteado la posibilidad de que al igual que los Licinii atestiguados en Laminium, fuese un inmigrante o descendiente de inmigrantes ${ }^{13}$, teniendo presente además la probable municipalización flavia de la ciudad ${ }^{14}$. Diversos hallazgos arqueológicos ${ }^{15}$ vienen a

Vid., FHA, IV, pág. 177.

8 En Ptolomeo (II, 6, 57) se cita una $K o v \delta \alpha \beta \sigma \rho \alpha, ~ ' \gamma L^{\prime \prime} \gamma^{\prime \prime} \mu L^{\prime \prime}$ entre los núcleos celtibéricos a continuación de Segóbriga; sobre la hipotética identificación con Consabura, vìd., A. TOvaA, Iberische Landeskunde..., op. cit., págs. 222-223.

$\theta$ CIL, II, 4211: P.H.C. / L. Domitio / M. fil. Serg. / Dentoniano / iudic. dec. V. equo / publico. per. Traian. / Ilvir. munic. Consaburon / flam[i]n. perpet. tribun. milit. / cohort. / Astur. Gallaeciae / et. Mauretan. Tingit. / flam. P.H.C.; H. Dessau, ILS, II, pág. 691, n. ${ }^{\circ} 6936$; J. VIVEs, Inscripciones latinas de la España romana, Barcelona, 1971, pág. 185, n. 1586; G. Alfolor, Flamines Provinciae Hispaniae Citerioris, Madrid, 1973 , pág. $69, n .^{\circ} 20$; Id., Die römischen Inschriften von Tarraco, Berlín, 1975, pág. 149, n. ${ }^{\circ}$ 271. También Consaburensis se atestigua en CIL, II, 2166: Q. Domitius / Q.L. Macer / Consaburensis / L. p. in fronte XV/in agro. p. XX; J. VIVES, Inscripciones latinas..., op. cit., pág. 487, n. $^{\circ} 5305$.

10 En relación a los cargos ocupados por Dentonianus, vid., G. AlföldY, Flamines..., op. cit., págs. 33 y 69; J.F. RodRiguez NEILA, “Los jueces de las cinco decurias oriundos de la España romana. Una contribución prosopográfica", HAnt, VIII, 1978, págs. 26-28.

11 H. Galsterer, Untersuchungen..., op. cit., pág. 70, n. 27.

12 Vid., W. KuBITSCHEK, De romanorum tribuum origine ac propagatione, Wien, 1882, pág. 171 ; Id., Imperium romanum tributim discriptum, Wien, 1889, pág. 193. Según R. WiEgels, Die Tribusinschriften..., op. cit., pág. 108, sería inusual que los ciudadanos romanos de Consabura hubieran sido asignados a dicha tribu.

13 Véase G. Alfoldy, Römischen Städtewesen..., op. cit., pág. 54; M. P. GONZÁLEZ-CONDE, Romanidad e indigenismo en Carpetania, Alicante, 1987, págs. 97 y 110; Id., "L. Domitius Dentonianus y la promoción jurídica de Consabura", HAnt., XIII, 1966-89, págs. 58 y 66.

$14 R E$, IV $, 1,1900$, col. 889; M. ${ }^{a}$ P. Gonzalez-Conde, Romanidad..., op. cit., págs. 99; Id., "L. Domitius...", art. cit., págs. 56-61; G. ALFoLDY, Römisches Städtewesen..., op. cit., pág. 53; J.M. ABASCAL, U. ESPINOSA, La ciudad hispano-romana..., op. cit., págs. 72 y 74 , fig. 9.

is Vid., al respecto, J. JIMÉNEZ DE GREGORIO, “Hallazgos arqueológicos en la provincia de Toledo", AEArq., 36, 1963, págs. 228 ss.; F.J. GiLES PACHECO, "Contribución al estudio de la arqueología toledana. Hallazgos hispanorromanos en Consuegra", Anales Toledanos, 5, 1971, págs. 139-165; J.A. GARCIA-DIEGO, “Una presa romana en Consuegra», Agua, 90, 1975, págs. 2-9; J.A. GaACIA-DiEgo ET ALII, "Nuevo estudio sobre la presa romana de Consuegra". Rev. de Obras Públicas, 1980, págs. 487-505; C. FeRnández CASADO, Ingeniería hidráulica romana, Madrid, 1983. 
confirmar su localización en Consuegra, a la vez que constatan la entidad que, paralela a su municipalización, llegaría a tener este núcleo.

Dentro de este ámbito territorial que nos ocupa, Caesarobriga ${ }^{16}$ constituye otro de los núcleos de status privilegiado. Plinio menciona a los caesarobrigensis como stipendiarii de Lusitania (Stipendiariorum quos nominari non pigeat,... Caesarobrigensis,...) ${ }^{17}$; sin embargo esta comunidad, lograría obtener la condición de municipio ${ }^{18}$, como se pone de manifiesto a través de la inscripción funeraria (CIL, II, 896) de L. Annius Placidus ${ }^{19}$ en la que se deja constancia de las magistraturas por éste ocupadas (D.M.S. / L. Annio. Placi / do. Quir. Caesa / robrig. an. XL / aedil. quaesto / ri. Ilviro. ter / Domitia. Attia / marito. optimo / fecit.); también se posee el testimonio de CIL, II, 895 sobre Domitia Proculina, flaminica provinc(iae) Lusitani(ae) y de su propio municipio ${ }^{20}$. La referencia, además, a la tribu Quirina ${ }^{21}$ documentada en CIL, II, 896, CIL, II, 913 y CIL, II, 5320, ha permitido fijar la promoción jurídica de Caesarobriga dentro de la obra de municipalización flavia ${ }^{22}$. A pesar, por otro lado, de los problemas que plantea su omisión en las fuentes antiguas itinerarias ${ }^{23}$, en base a los hallazgos epigráficos y

pág. 147; J.A. GAACÍA-DIEGO ET ALII, "Estudio conjunto sobre la presa romana de Consuegra", Rev. de Obras Públicas, 1983, págs. 673-688; J.C. Fernández-Layos, $H .{ }^{a}$ de Consuegra, I. Edad Antigua, Toledo, 1983, págs. 83 ss.; A. BLANCO FREJEIRO, “Presa romana de Consuegra (Toledo). Declaración de monumento histórico-artistico", BRAH, CLXXX, 1983, págs. 191-192.

${ }_{16}$ En cuanto al nombre, constituye uno de los diversos topónimos constatables en la Peninsula con sufijo en -briga, vid., en este caso, A. HOLOER, Alt-Celtischer Sprachschatz, 1, Leipzig, 1896, pág. 678; también J. UNTERMANN, Sprachräume und Sprachbewegungen in vorrömischen Hispanien, Wiesbaden, 1961, pág. 16 y map. $3 ;$ M. ${ }^{2}$ L. AlBERTOS FIRMAT, "Los topónimos en -briga en Hispania", Veleia, 7, 1990, pág. 134.

17 Plin., N.h., IV, 113.

18 Vid., RE, III, 1897, col. 1304; R.K. MCELDERRY, “Vespasian's...», art. cit., pág. $73 ; \mathrm{H}$. Galsterer, Untersuchungen..., op. cit., pág. 68; B. GaLSTERER-Kröll, "Untersuchungen zu den Beinamen...", art. cit., pág. 110, n. ${ }^{\circ} 154$; A. Tovar, Iberische Landeskunde, Die Völker und die Städte des antiken Hispanien, 2. Lusitanien, Baden-Baden, 1976, pág. 236; G. ALFöor, Römisches Städtwesen..., op. cit., pág. 58-59.

$19 \mathrm{Cf}$. J. Francisco Martin, «Los magistrados municipales de Lusitania durante el Alto Imperio", Memorias de Historia Antigua, I, 1977, pág. 234.

20 CIL, II, 895: Domitia. L. f. / Proculina / flaminica. provinc / Lusitan. et. flam / municipi. sui. prima / et perpetua. Sobre dicha flaminica, posiblemente emparentada con Domitia Attia de Cll_, II, 896, vid., R. Etienne, Le culte impérial dans la Péninsule lbérique d'Auguste a Dioclétien, Paris, 1958, págs. 166,167 y 239.

21 Cf. W. KUBITSCHEK, De romanorum..., op. cit., pág. 157; Id., Imperium romanum.., op. cit., pág. 184.

22 Véase R. WIEGElS, Die Tribusinschriften..., op. cit., pág. 74; G. ALFÖLDY, Römisches Städtewesen..., op. cit, pág. 59; J.M. ABASCAL, U. ESPINOSA, La ciudad hispano-romana.., op. cit., págs. 74 , fig. 9, y 77 .

${ }_{23}$ Vid., al respecto, M. Fernández Miranda et ALII, "Alio itinere ab Emerita Caesaraugusta. La via romana entre Talavera de la Reina y Toledo y la implantación humana en el valle medio del río Tajo", Simposio sobre la red viaria en la Hispania romana, Zaragoza, 1990, págs. 155-163; Id., 
arqueológicos, en la actualidad se mantiene su tradicional identificación en Talavera de la Reina ${ }^{24}$.

Entre los municipios flavios de este área geográfica, cabe citar también a Segontia ${ }^{25}$. Plinio ${ }^{26}$ incluye a este núcleo entre los oppida de los arévacos; asimismo es mencionado por Livio (XXXIV, 19, 10), en relación a su asedio llevado a cabo por Catón en el 195 a.C. ${ }^{27}$. Segontia ejercerá además una destacable función como nudo viario ${ }^{28}$, siendo recogido en el Itinerario de Antonino (It. Ant., 436, 5; It. Ant., 438, 12), y en el Anónimo de Rávena (309, 18: Seguntia); posiblemente esta importancia desde el punto de vista de las comunicaciones, facilitase su promoción jurídica constatable en la inscripción (CIL, II, 4195) del seguntino C. Atilius Crassus ${ }^{29}$ quien ostenta el flaminado ${ }^{30}$ provincial de la Citerior: C. Atilio / C. f. Quir. / Crasso / Segontino / omnib(us) honor. / in Re Pub. sua / functo flam. /

"Indigenismo y romanización en la cuenca media del Tajo. Planteamiento de un programa de trabajo y primeros resultados", Actas del Primer Congreso de Arqueologia de la provincia de Toledo, Toledo, 1990, págs. 15 ss. También véase G. ARIAS, Repertorio de caminos de la Hispania romana, 1987, págs. 124-126 y 367-368; Id., ME, 19, 1989, págs. 22-23; ME, 27, 1990, pág. 6; ME, 36 , 1992, pág. 23; ME, 41, 1992, pág. 9.

24 Cf. F. FITA, BRAH, 2, 1882 , págs. 299 ss.; BRAH, 4, 1884, págs. 209-210; E. HüBNER, RE, III, 1897, col. 1304; F. Fuidio Rodriguez, Carpetania romana, Madrid, 1934, pág. 57; M. ${ }^{\text {a } P .}$ GONZALEZ-CONDE, “Elementos para una delimitación entre vettones y carpetanos en la provincia de Toledo", Lucentum, 5, 1986, págs. 87-93; G. ALföLDY, Römisches Städtewesen..., op. cit., pág. 58; en el mismo sentido también, J. MANGAS, J. CARROBLES, «La ciudad de Talavera de la Reina en época romana", Actas de las Primeras Jornadas de Arqueología de Talavera de la Reina y sus tierras, Toledo, 1992, págs. 98-9; M. ${ }^{a}$ J. RuBio FuENTEs», "Caesarobriga, ciudad romana de la Lusitania", Actas /I Congresso Peninsular de Historia Antiga, Coimbra, 1993, págs. 567-580; J. MAngas, J. CarRobles, "Ciudades del área de la provincia de Toledo en época republicana", Italia e Hispania en la crisis de la República romana, Madrid, 1998, pág. 244.

25 En relación al carácter del nombre vid., A. HOLDER, Alt-Celtischer..., op. cit., vol. II, págs. 1448-9; también M. FERnández-Galiano, Sobre el nombre de Sigüenza, Sigüenza, 1973, págs. 13 ss.

${ }_{26}$ N.h., III, 27: Arevacis nomen dedit fluvius Areva: horum VI oppida, Secontia et Uxama,

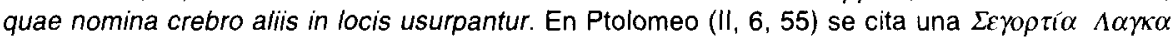
que ha llegado a ser identificada por algunos con Segontia, véase vgr., F. FITA, "Inscripciones ibéricas y romanas de la diócesis de Sigüenza. Observaciones críticas", BRAH, LVIII, 1911, pág. 326; J. UNTERMANN, "Zur Gruppierung der hispanischen Reitermünzen mit Legenden in iberischer Schrift", $M D A I(M), 5,1964$, pág. 110.

${ }_{27}$ Liv., XXXIX, 19, 10: consul ubi hostis ad pugnam elicere nequit, primum praedatum sub signis aliquot expeditas cohortis in agrum integrae regionis ducit, deinde audito Seguntiae Celtiberum omnis sarcinas impedimentaque relicta eo pergi ducere ad oppugnandum. Por otra parte, A. SCHULTEN llegaría a proponer una equivocación en Livio, XXVI, 20,6, al confundir según él Saguntum con Segontia, vid., FHA, III, pág. 98.

28 Vid., J.M. AbASCAL PALAZÓn, Vias de comunicación romanas de la provincia de Guadalajara, Guadalajara, 1982, págs. 29, 50-51, 85 ss.

29 J. Vives, Inscripciones latinas..., op. cit., pág. 186, n. ${ }^{\circ} 1604$; G. AlföLDY, Die römischen.... op. cit., págs. 141-142, n. 258.

30 Vid., R. ETIENNE, Le culte impérial..., op. cit., pág. 141; G. AlföloY, Flamines..., op. cit., pág. $65, \mathrm{n}^{\circ} 7$. 
Prov. Hisp. Citer. / P.H.C. La pertenencia de Atilius Crassus a la tribu Quirina ${ }^{31}$ hace que se mantenga la municipalización bajo los Flavios ${ }^{32}$ de Segontia, cuyo antiguo oppidum se sitúa en el cerro de Villavieja ${ }^{33}$ a tres Km. de la actual Sigüenza.

Testimonios de municipalidad ofrecen igualmente tanto Toletum como Segobriga. La primera cita a Toletum es recogida por Livio (XXXV, 7) al relatar las operaciones llevadas a cabo por M. Fulvio Nobilior en el 193 a.C. (maiores gestae res a M. Fulvio. is apud Toletum oppidum cum Vaccaeis Vectonibusque et Celtiberis signis collatis dimicavit); también Livio denomina a Toletum como parva urbs, sed loco munito (XXXV, 22, 5) en la narración del sitio y ocupación de la ciudad por M. Fulvio en el año 192 a.C. ${ }^{34}$, para posteriormente volver a referirse a este núcleo (XXXIX, 30), al describir las campañas de L. Quinctio Crispino y C. Calpurnio Pisón sobre Carpetania ${ }^{35}$. Toletum es igualmente mencionado como mansio (It. Ant., $438,7 ; 446,7)$ en las vías respectivas del Itinerario de Antonino Alio itinere ab Emerita Caesarea Augusta e Item a Liminio Toletum, y por el Anónimo de Rávena $(312,10)$ con el nombre de Toleton ${ }^{36}$. Por su parte

31 W. KuBITSCHEK, De romanorum.., op. cit., págs. 179, 185; Id., Imperium romanum..., op. cit., pág. 199; F. FITA, “Inscripciones...", art. cit., pág. 331; R. WIEGELS, Die Tribusinschriften..., op. cit., pág. 135.

32 R.K. MCELDERRY, "Vespasian's...”, art. cit., pág. 76; J.M. ABASCAL, “En torno a la promoción jurídica de la Segontia de los Arévacos", Gerion, 4, 1986, págs. 213-223; G. Alföldy, Römischen Städtewesen..., op. cit., págs. 65-66; J.M. ABASCAL, U. EsPINOSA, La ciudad hispano-romana..., op. cit., págs. 72 y 74; J.M. CASILLAS ET ALII, "La municipalización de Segontia", Actas // Congresso Peninsular de Historia Antiga, Coimbra, 1993, págs. 625-632.

33 Cf. A. Schulten, RE, II, 1, 1921, col. 1083; J.A. CeÁn Bermúdez, Sumario de las antigüedades romanas que hay en España, Madrid, 1832, pág. 155-6; F. FuIDIo Rodriguez, Carpetania..., op. cit., pág. 40; J.M. ABASCAL, Vias de comunicación..., op. cit., pág. 50; G. Alföldy, Römischen Städtewesen..., op. cit., pág. 65; A. Tovar, lberische Landeskunde..., op. cit., vol. III, pág. 365.

${ }_{34}$ Liv., XXXV, 22, 5: tum in Oretanos progressus et ibi duobus potitus oppidis Noliba et Cusibi ad Tagum amnem ire pergit. Toletum ibi parva urbs erat, sed loco munito. eam cum oppugnaret, Vectonum magnus exercitus Toletanis subsidio venit. cum is signis collatis prospere pugnavit et fusis Vectonibus operibus Toletum cepit.

35 Liv., XXXIX, 30: eodem anno in Hispania praetores $C$. Calpurnius et L. Quinctius, cum primo vere ex hibernis copias eductas in Baeturia iunxissent, in Carpetaniam, ubi hostium castra erant, progressi sunt, communi animo consilioque parati rem gerere. haud procul Dipone et Toleto urbibus inter pabulatores pugna orta est. quibus dum utrimque subvenitur a castris, paulatim omnes copiae in aciem eductae sunt.

36 Sobre el carácter del nombre, vid., A. HoldER, Alt-Celtischer..., op. cit., vol. II, pág. 1871; A. SCHULten, RE, VI, 2, 1937, col. 1673; J. HuBSCHMID, "Toponimia prerromana", ELH, I, Madrid, 1960, pág. 468; R. MEnÉndez PIDAL, Toponimia prerrománica hispánica, Madrid, 1968, págs. 54, 58 y 173; A. Tovar, Iberische Landeskunde..., op. cit, vol. III, pág. 229; F. VILLAR, “Talabara, Talavera, Toledo", Studia Palaeohispanica et Indogermanica J. Untermann ab amicis oblata, Barcelona, 1993, págs. 292-294; Id., Estudios de Celtibérico y de toponimia prerromana, Salamanca, 1995, pág. 217; también véase al respecto, F. JIMÉNEz de Gregorio, Los pueblos de la provincia de Toledo hasta finales del siglo XVIII, T. V, Toledo, 1986, págs. 69-71. 
Ptolomeo la incluye $\left(T \omega \hat{\omega} \lambda \eta \tau o v, \imath^{\prime} \mu \alpha\right)^{37}$ entre las ciudades carpetanas, catalogándose además por Plinio ${ }^{38}$ a los toletani como estipendiarios del conventus Carthaginensis. Pero de la existencia de un Senado municipal a través de la fórmula $d$ (ecreto) $d$ (ecurionum) ${ }^{39}$, y de seviri ${ }^{40}$, constatables en dos epígrafes honoríficos, puede deducirse su condición de municipium ${ }^{41}$, aun cuando resulte dificultoso poder establecer con plena seguridad el momento en que dejaría de ser ciudad estipendiaria ${ }^{42}$. Toletum por otra parte mostraría un notorio desarrollo urbano, atestiguado en los restos arqueológicos del circo ${ }^{43}$, acueducto ${ }^{44}$, etc.

37 Ptol., II, 6, 56. La forma Tád $\lambda$ tov aparece en los siguientes códices: Parisiensis, 1401, Parisiensis Supplem., 119, Parisiensis, 1402, Parisiensis, 1403, Parisiensis Coislin, 337, Vindobonensis, 1, Oxoniensis Seldanus, II, 46, Venetus, 516, Mediolanensis, D, 527, Vaticanus. 177, Vaticanus, 178, Vatic. Palatinus, 388, Vatic. Christinae reg. 82, S. Gregorii in monte Coelio, Florentinus Laurentianus, XXVIII, 49, Scorialensis, $\Omega, 1,1$, Constantinopolitanus.

${ }_{38}$ Plin., N.h., III, 25: ..., Carpetaniae Toletani Tago flumini inpositi. Por su parte Grattio (Cyneg. 341) hace referencia al cultrum Toletanum, vid., FHA, VIII, pág. 132 y A. SCHULTEN, Geografía y etnografia antiguas de la Península lbérica, II, Madrid, 1963, pág. 334. Otras fuentes, Iul. Honor., Cosmogr., pág. 34, 12: Toletum oppidum; Cosmogr. Aeth., pág. 79, 13: Toletum (Geographi Latini Minores, ed. A. Riese, Hildesheim, 1964).

${ }_{39}$ ClL, II, 3073: Imp. Caes / M. IVlio. Philippo / Pio. Fel. Aug / Pont. max. Trib. / Pot. p. p. consul / Toletani. devotis / simi Numini / maiestate / que eius / $d$. $d$.; J. Vives, Inscripciones latinas..., op. cit., pág. 139, n. ${ }^{\circ} 1177$; también cf. R. ETIENNE, Le culte impérial..., op. cit., págs. 311-2, 507.

${ }_{40}$ Véase S. CORTÉS ET ALII, «Nuevas inscripciones romanas del Museo de Santa Cruz de Toledo", Museos, 3, 1984, pág. 77, n. ${ }^{\circ} 6$ : ...] usor / [...]or sevir / circensib(us) editis / D(ecreto) d(ecurionum); G. ALFöldY ofrece la lectura: ob / /hoJnor(em) IIII/vir(atus) / circensibus editis / $d($ ono) d(edit), cf. Römisches Städtewesen..., op. cit., pág. 61.

41 Vid., al respecto, M. a P. GONZALEz-CONDE, Romanidad.., op. cit., págs. 57 ss.; G. Alfoldy, Römisches Städtewesen..., op. cit., págs. 59-62; J. MANGAS, J. ALVAR, "La municipalización de Carpetania", Toledo y Carpetania en la Edad Antigua, Toledo, 1990, págs. 83-96; D. PLACIDO ET ALII, “Toletum", DArch., 1992, págs. 269 ss.

42 Mientras M. ${ }^{a}$ P. GONZALEZ-CONDE y G. ALFöLDY estiman como probable la municipalización flavia de Toletum, vid., nota 42, J. MANGAS, "La municipalización...", art. cit., págs. 92 ss. considera que existen una serie de hechos que podrian hacer pensar que la municipalización de Toletum fue anterior.

43 M. Castaños et alli, "Excavaciones en Toledo. Memoria de los trabajos efectuados en el circo romano", MJSEA, 96, 1928; F. SAN ROMÁN ET ALII, “Excavaciones en Toledo. Memoria de los trabajos efectuados en el circo romano", MJSEA, 109, 1930; A. REY PASTOR, El circo romano de Toledo, Toledo, 1932; F.J. Wiseman, Roman Spain, London, 1956, pág. 132; P. PiernaviejA, "Los circos de Hispania", Symposium de Arqueología Romana, Barcelona, 1977, pág. 319; J.H. Humphrey, Roman Circuses. Arenas for Chariot racing, London, 1985, págs. 350-360; F.J. SÁNCHEZ-PALENCIA ET ALII, "Estratigrafía y arquitectura del circo romano de Toledo", I Congreso de H. de Castilla-La Mancha, T. IV, 1988, págs. 225-236; F.J. SÁnChEZ-PALEnCIA, M. a J. Sáinz PASCUAL, El circo romano de Toledo: estratigrafía y arquitectura, Toledo, 1988; F.J. SÁNCHEZPALENCIA ET ALII, "El circo romano de Toledo", Actas del Primer Congreso de Arqueología de la provincia de Toledo, Toledo, 1990, págs. 253-369; F.J. SÁnCHEZ-PALENCIA ET ALII, "Circo Romano", Toledo. Arqueología en la ciudad, Toledo, 1996, págs. 25-27.

44 C. FERnÁNDEZ CASADO, Acueductos romanos en España, Madrid, 1972; Id., Ingeniería hidráulica romana, Madrid, 1983, págs. 514-515; también véase, F. Fuidı Rodriguez, Carpetania romana, Madrid, 1934, págs. 70-72; J. Porres, El abastecimiento de aguas a Toledo, Toledo, 1970; 
En cuanto a Segobriga ${ }^{45}$, en Estrabón se cita a $\Sigma \varepsilon \gamma o \beta \rho i ́ \gamma \alpha$ como ciudad

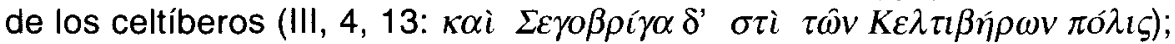
también entre los núcleos celtíberos la incluye Ptolomeo (II, 6, 57: $\left.\Sigma \eta \gamma \delta ́ \beta \rho \imath \gamma \alpha, \gamma^{\prime} L^{\prime \prime} \mu^{\prime} \gamma o^{\prime \prime}\right){ }^{46}$, considerándose por Plinio (III, 25) caput Celtiberiae. Por su parte Frontino (Strat., III, 10, 6 y III, 11, 4) hace referencia a los segobrigenses con motivo de los ataques que éstos experimentarían por parte de Viriato a mediados del siglo II a.C. ${ }^{47}$. Segobriga va a poseer una notoria importancia estratégica debido a su situación ${ }^{48}$, siendo mencionada en la vía recogida por el Anónimo de Rávena $(313,11$ : Sigobriga), entre Caraca y Puteis. Plinio ${ }^{49}$ la incluye entre los núcleos

F. CHUECA GoITIA, «Abastecimiento romano de aguas a Toledo. Declaración de monumento histórico-artístico", $B R A H, 179,1982$, págs. 385-386. Además y en relación al castelum aquae vid., J.A. Garcia-Diego, "La cueva de Hércules", Rev. de Obras Públicas, 1974, págs. 683-700; J. Porres, Rev. de Obras Públicas, 1975, págs. 333 ss.; J.A. Garcia-Diego, J. Porres, Rev. de Obras Públicas, 1977, págs. 727-730; C. Fernandez CASAdo, Rev. de Obras Públicas, 1977, págs. 809812; Id., Ingenieria hidráulica..., op. cit., pág. 247. Recientemente y en general, véase F. ARANDA ALONSO ET ALII, El sistema hidráulico romano de abastecimiento a Toledo, Toledo, 1997.

45 Sobre el nombre vid., A. HOLDER, Alt-Celtischer..., op. cit., vol. II, págs. 1444-46; también, J. Untermann, Sprachräume..., op. cit., pág. 19 y map. 3; M. ${ }^{a}$ L. Albertos Firmat, "Los topónimos...», art. cit., págs. 140-141; F. VILLAR, Estudios..., op. cit., págs. 121-2, 126, 132, 137, 153-4, 156, $161,168,170$ y 174 .

${ }_{46}$ La forma $\Sigma \eta \gamma o ́ \beta \rho ı t \alpha$ aparece en el códice Parisiensis, 1402, Mediolanensis, D, 527,

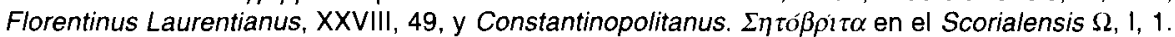
$\Sigma_{i} \gamma \delta \beta \rho \imath \tau \alpha$ en el Barberinus, $S$. Gregorii in monte Coelio, Florentinus Abbatiae; $\Sigma_{\imath} \gamma o \beta \rho i \gamma \alpha$ en el Florentinus Laurentianus, XXVIII, 9, Florentinus Laurentianus, XXVIII, 38, Florentinus Laurentianus, XXVIII, 42. En cuanto a las coordenadas, $\left(\gamma^{\prime} \varsigma^{\prime \prime}\right.$ se nos ofrece en los códices Athous Vatopedi monasterii, Venetus, 383, Venetus, 516, Mediolanensis, D, 527, Vaticanus, 177, Vaticanus, 178, Florentinus Laurentianus, XXVIII, 49, Constantinopolitanus. $\mu^{\prime} \gamma o^{\prime \prime}$ en el Venetus, 383, Venetus, 516, Mediolanensis, D, 527, Vaticanus, 177, Vaticanus, 178, Florentinus Laurentianus, XXVIII, 49, Constantinopolitanus. $\mu \gamma^{\prime} \gamma^{\prime \prime}$ en el Parisiensis Supplem., 119, Parisiensis, 1402, Athous Vatopedi monasterii, Vindobonensis, 1, Oxoniensis Seldanus, II, 45, Florentinus Abbatiae, 2380, S. Gregorii in monte Coelio, Scorialensis $\Omega, 1,1 . \mu \gamma^{\prime} \gamma^{\prime \prime} \zeta^{\prime \prime}$ en el Barberinus. $\mu L^{\prime \prime} \gamma^{\prime \prime}$ en el Vaticanus, 191 , Florentinus Laurentianus, XXVIII, 9, XXVIII, 38, XXVIII, 42.

47 Frontin., Strat., III, 10, 6: Viriathus disposito per occulta milite paucos misit qui abigerent pecora Segobrigensium. ad quae illi vindicanda cum frequentes procurrissent simulantesque fugam praedatores persequerentur deducti in insidias caesique sunt. III, 11, 4: Viriathus, cum tridue iter discedens confecisset, idem illud uno die remensus securos Segobrigenses et sacrificio cum maxime occupatos oppressit. Véase no obstante, la interpretación de L. GARCiA MORENO, «Infancia, ju-

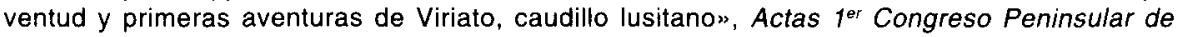
Historia Antigua, vol. II, S. de Compostela, 1988, pág. 381.

${ }_{48}$ Vid., S. Palomero Plaza, "Las vías romanas de Segóbriga y su contexto en las vías romanas de la actual provincia de Cuenca", Homenaje al Prof. Martín Almagro Basch, T. III, Madrid, 1983, págs. 247-261; Id., Las vías romanas en la provincia de Cuenca, Cuenca, 1987, págs. 53 ss.

${ }_{49}$ Plin., N.h., III, 25; Plinio vuelve a referirse a Segobriga en relación a la riqueza y explotación de lapis specularis, vid., N.h., XXXVI, 160: Specularis vero, quoniam et hic lapidis nomen optinet, faciliore multo natura finditur in quam libeat tenues crustas. Hispania hunc tantum citerior olim dabat, nec tota, sed intra $C$ passuum circa Segobrigam urbem,... También al respecto $S$. Isid. Etym., 16, 4, 37: specularis lapis vocatus est quod vitri more transluceat, repertus primum in Hispania citeriore circa Segobricam urbem. invenitur enim sub terra et effossus exciditur. finditur in quamlibet tenues crustas. 
estipendiarios pertenecientes al conventus Carthaginensis, llegando, no obstante, a alcanzar estatuto municipal ${ }^{50}$ como se evidencia a través de las referencias epigráficas, entre otras, de seviri y aedilis (vgr., CIL, II, 3103; CIL, II, 3104; CIL, II, 3112) ${ }^{51}$. Se puede fijar claramente la municipalización de Segobriga en época augustea ${ }^{52}$, como se corresponde además con la tribu Galeria ${ }^{53}$ atestiguada (vid., vgr., ClL, II, 3126; CIL, II, 5881 , etc...) ${ }^{54}$. Dicha transformación tendría una importante repercusión en la ciudad desde el punto de vista urbanístico ${ }^{55}$, constatable en el gran conjunto arqueológico de Cabeza de Griego (Saelices) conservado ${ }^{56}$.

Municipios augusteos son también considerados Valeria y Ercavica ${ }^{57}$. En Ptolomeo Valeria ${ }^{58}$ es citada (II, 6, 57: Oú $\left.\alpha \lambda \varepsilon \rho i \alpha, \imath \beta L^{\prime \prime} \mu^{\prime} \gamma^{\prime} \imath \beta^{\prime}\right){ }^{59}$ entre

50 Vid., G. Alföloy, Römisches Städtewesen..., op. cit., págs. 76-79; J.M. ABASCAL, U. Espinosa, La ciudad hispano-romana..., op. cit., pág. 66.

51 Cf. M. Almagro Basch, Segóbriga II. Inscripciones ibéricas, latinas paganas y latinas cristianas, Madrid, 1984, págs. 96-98, 100-102, 114-115, n. ${ }^{\circ} 24-26$ y 34. También y en relación a seviri Augustales, M. Almagro BASCH, op. cit., págs. 117-118, $\mathrm{n} .^{\circ} 36$. Por lo que respecta a la magistratura de III/vir atestiguada, vid., G. Alfoldr, Römisches Städtewesen..., op. cit., pág. 79.

52 G. Alföldy, Römisches Städtewesen..., op. cit., págs. 79-80; J.C. Olivares Pedreño, Conflicto politico y promoción juridica de comunidades en el Occidente romano (133 a.C.-174 d.C.), Alicante, 1998, pág. 222.

53 Vid., W. Kubitschek, De romanorum..., op. cit., pág. 179; Id., Imperium romanum..., op. cit. pág. 199; R. WIEGELS, Die Tribusinschriften..., op. cit., págs. 134-135.

54 Cf. M. Almagro Basch, Segóbriga II..., op. cit., págs. 112-114, 188-191, 205-206, 216-217. n. ${ }^{\circ} 33,66,78$ y 86 . También y a favor de la municipalización augustea de Segobriga vid., las dedicaciones honoríficas de CIL, II, 3102; CIL, II, 3103; CIL, II, 3104

55 Véase M. Almagro Gorbea, "La urbanización augustea de Segóbriga", Stadtbild und Ideologie. Die Monumentalisierung hispanicher Städterzwischen Republik und Kaiserzeit, München, 1990, págs. 207-218; Id., “La romanización de Segóbriga», DArch., 1992, págs. 279 ss.; M. Almagro Gorbea, A. Lorrio, Segóbriga III. La Muralla Norte y la Puerta Principal. Campañas, 1986-1987, Cuenca, 1989, págs. 173 ss.; M. Almagro GorbeA, J.M. AbAsCAL, "Segóbriga", Hispania. El legado de Roma, Zaragoza, 1998, pp. 423-427.

56 Además de la bibliografía citada en nota anterior, vid., M. AlmaGro BASCH, Segóbriga, ciudad celtibérica y romana. Guía de las excavaciones y Museo, Madrid, 1975; más recientemente, M. Almagro Gorbea, J.M. Abascal., Segóbriga y su conjunto arqueológico, Madrid, 1999. Sobre la problemática de su ubicación cf., M. Almagro BASCH, Segóbriga I. Los textos de la Antigüedad sobre Segóbriga y las discusiones acerca de la situación geográfica de aquella ciudad, Madrid, 1983; también y en relación a la discutida identificación de Segobriga, con la Sekobirikes de las series numismáticas, véase un breve resumen en P.P. Ripollés AlEgRE, J.M. Abascal PaLAZón, Las monedas de la ciudad romana de Segóbriga (Saelices, Cuenca), Madrid, 1996, págs. 14-21.

57 Vid., J. M. a SOLANA SátNZ, "Colonización y municipalización bajo César y Augusto", Aspectos de la colonización y municipalización de Hispania, Mérida, 1989, págs. 95-96; J.C. Olivares Pedreño, Conflicto político y promoción juridica..., op. cit., pág. 222.

58 En cuanto al nombre, se ha supuesto su relación con $\mathrm{C}$. Valerio Flaco quien obtendría victorias sobre Celtiberia, vid., RE, VII, 2, 1948, col. 2281; A. Tovar, Iberische Landeskunde..., op. cit., vol. III, pág. 220 .

59 La graduación $\mu^{\prime} \gamma^{\prime \prime} \beta^{\prime \prime}$ se ofrece en los códices Vaticanus, 191, Florentinus Laurentianus, XXVIII, 9, XXVIII, 38, XXVIII, 42, Mediolanensis, D, 527, Florentinus Laurentianus, XXVIII, 49, y Constantinopolitanus. $\mu \gamma^{\prime \prime} \gamma^{\prime \prime}$ en el Parisiensis, 1403, Parisiensis Coislin, 337, Parisiensis, 2423, Oxoniensis Seldanus, II, 46, Vatic. Palatinus, 314. 
las ciudades celtíberas, y Plinio ${ }^{60}$ se refiere a los valerienses entre los que gozan de derecho latino antiguo del conventus Carthaginensis. Es probable que pese a que las fuentes lo silencien, se viese afectada por las campañas que T. Sempronio Graco llevase a cabo en esta zona de Celtiberia, teniendo presente además el hallazgo de un tesorillo ${ }^{61}$ cuya fecha de ocultación se calcula en torno al 179 a.C. Epigráficamente se confirma su condición privilegiada ${ }^{62}$ a través vgr., de la magistratura de IIIIvir constatada ${ }^{63}$, siendo la tribu Galeria ${ }^{64}$ la de sus ciudadanos. Los numerosos hallazgos y restos arqueológicos de estructuras arquitectónicas, ponen de manifiesto la importancia que el enclave de Valeria alcanzaría en época romana ${ }^{65}$.

60 Plin., N.h., III, 25: oppidani Latii veteris... Valeriensis; vid., H. GaLsTERER, Untersuchungen..., op. cit., pág. 72, n. ${ }^{\circ}$ 73; B. Galsterer-KRÖLL, “Untersuchungen zu den Beinamen...", art. cit., pág. $114, \mathrm{n}^{\circ} 223$.

61 Cf. M. Almagro Basch, «El tesorillo de Valera de Arriba (Cuenca)», Numario Hispánico, VII, 1958, págs. 5-14; Id., “Dos nuevas piezas del tesoro de Valera de Arriba (Cuenca)", Numario Hispánico, IX, 1960, págs. 213-214; M. Almagro Basch, M. Almagro GorbeA, “El tesorillo de Valeria. Nuevas aportaciones», Numisma, 71, 1964, págs. 25-47.

62 Ya el P. Flórez, España Sagrada, VIII, pág. 197 atribuia a Valeria carácter municipal.

63 Al igual que en Segobriga, en Valeria también se atestigua la existencia de IIIlvir, véase G. ALFöloY, Römisches Städtewesen..., op. cit., pág. 87; igualmente al respecto J.M. ABASCAL, U. EsPINOSA, La ciudad hispano-romana..., op. cit., pág. 132. Por otra parte y en cuanto a la $r(e s)$ p(ublica) Val(eriensis) vid., CIL, II, 3181; también M. OsunA ET ALII, Valeria Romana, I, Cuenca, 1978, págs. $116-117, n{ }^{\circ} 38$; A. Rodriguez COLMENERO, "Cuenca romana. Contribución al estudio epigráfico", Lucentum, I, 1982, pág. 216, n. ${ }^{\circ} 36$.

64 Vid., W. KuBitscheK, De romanorum..., op. cit., págs. 182 y 186; Id., Imperium romanum..., op. cit., pág. 200; R. WIEGELs, Die Tribusinschriften..., op. cit., págs. 142-143.

65 Véase J. LaRRañaga, "Ruinas de Valeria», NAH, 2, 1953, págs. 153-155; F. Suay, "Informes de los hallazgos arqueológicos encontrados en la ciudad romana de Valeria, en el período de tiempo comprendido entre el año 1952 a 1957", V CNA, Zaragoza, 1959, págs. 244246; M. Osuna Ruiz, "Hallazgos numismáticos de época augustea en Valeria (Cuenca)", Symposion de ciudades augusteas, II, Zaragoza, 1976, págs. 195-200; Id., "Avance de las excavaciones de Valeria y Ercavica. Campañas 1974-75", XIV CNA, (Vitoria, 1975), Zaragoza, 1977, págs. 1129-1131; M. Osuna, F. SuAv, "Valeria romana. Notas acerca de sus restos monumentales", Symposium de Arqueología Romana, Barcelona, 1977, págs. 293-296; M. OsuNA ET ALII, Valeria Romana, I, Cuenca, 1978; M. OsunA, "Valeria, cinco milenios de historia", Homenaje a Conchita Fernández Chicarro, Madrid, 1982, págs. 401-405; A. FuENTES, «Avance del Foro de Valeria (Cuenca)", Los Foros romanos de las provincias occidentales, Madrid, 1987, págs. 69-72; 1d., "La cronología del yacimiento hispanorromano de Valeria y su relación con otros análogos de la Meseta", Actas / Congreso $H_{.}{ }^{a}$ de Castilla-La Mancha, T. IV, 1988, págs. 211-223; Id., "Urbanismo privado y casas en Valeria", La casa urbana hispanorromana, Zaragoza, 1991, págs. 265-280; Id., "Valeria: Historia del yacimiento y resultado de las últimas investigaciones", Ciudades romanas en la provincia de Cuenca. Homenaje a Francisco Suay Martínez, Cuenca, 1997, págs. 103-131; J. CONCE LOPEZ, “Un conjunto de elementos arquitectónicos reutilizado en Valeria”, Ciudades romanas..., op. cit., págs. 133-147; M. CONTRERAS MARTíneZ, “El poblamiento periurbano de Valeria: aproximación a su territorium", Ciudades romanas..., op. cit., págs. 149-155; R. EsCOBAR FERNÁNDEZ, C. LIESAU, “Un ejemplo de espacio suburbano en Valeria: la zona pública de la Fuente Navarro", Ciudades romanas..., op. cit., págs. 157-167. 
Por su parte Ercavica ${ }^{66}$, es calificada por Livio (XL, 50) como nobilis et potens civitas ${ }^{67}$ al relatar su anexión por T. Graco. También es mencionada por Ptolomeo (II, 6, 57: 'E $\left.\rho \gamma \alpha o v ́ \imath \kappa \alpha, \imath \beta^{\prime} \gamma^{\prime \prime} \mu L^{\prime \prime} \delta^{\prime \prime}\right){ }^{68}$ entre los núcleos de Celtiberia, incluyéndose por Plinio (III, 24) los ergavicenses entre los popuii Latinorum veterum del conventus Caesaraugustanus ${ }^{69}$. Su status de municipio ${ }^{70}$ viene a constatarse claramente a través de emisiones monetales ${ }^{71}$ en las que se hace referencia explícita a dicho carácter, al igual que a algunos duoviri; asimismo el cargo de duunviro está atestiguado por lo que a la epigrafía respecta ${ }^{72}$, del mismo modo que la tribu Galeria ${ }^{73}$. A pesar de la discusión que su localización exacta llegara a plantear ${ }^{74}$, testimonios tanto arqueológicos como epigráficos y numismáticos permiten asegurar su ubicación en el Castro de Santaver ${ }^{75}$.

66 En relación al nombre, A. Holder, Alt-Celtischer..., op. cit., vol. I, pág. 1458.

67 Liv., XL, 50: Ergavica inde nobilis et potens civitas aliorum circa populorum cladibus territa portas aperuit Romanis.

68 La forma 'E $\rho \tau \alpha o u ́ t \kappa \alpha$ aparece en el códice Constantinopolitanus. 'E $\rho \gamma \alpha o ́ n \kappa \alpha$ en el Parisiensis, 2423. La graduación $t \beta^{\prime} L^{\prime \prime}$ queda patente en los códices, Florentinus Laurentianus, XXVIII, 9, XXVIII, 38, XXVIII, 42.

69 Véase al respecto la muy ilustrativa inscripción de $\mathrm{CIL}, \mathrm{II}, 4203$; J. VIVEs, Inscripciones latinas..., op. cit., pág. 156, n. ${ }^{\circ}$ 1310: M. Calpurnio M. f. / p(rov.) H. C. ex convent. / Caesar. Ercavic., / omnibus honorib. / in republica sua / functo, praefecto / cohortis primae / Biturgium / P.H.C.; G. AlföldY, Die Römischen..., op. cit., págs. 145-146, $\mathrm{n} .{ }^{\circ} 265$ ofrece la siguiente lectura: $M($ arco) Calp[urnio. f(ilio)] / Lu[po. flam(ini)] / p(rovinciae) H(ispaniae) c(iterioris) ex conven[t(u)] Caesar(augustano) Ercavic(ensi) / omnib(us) honorib(us) / in re publica sua / functo, praefecto / cohortis primae / Biturigum, / p(rovincia) H(ispania) c(iterior); también cf. R. ETIENNE, Le culte impérial..., op. cit., págs. 142, 146; G. ALFOLDY, Flamines..., op. cit., pág. 67, n. ${ }^{\circ} 14$,

70 H. Galsterer, Untersuchungen..., op. cit., pág. 70, n. ${ }^{\circ} 33 ; \mathrm{G}$. Alföldy, Römisches Städtewesen..., op. cit., págs. 66-68.

71 Vid., A. VIVES Y ESCUDERo, La moneda hispánica, IV, Madrid, 1926, págs. 109-110, lám. CLXII; O. GIL FARRÉS, La moneda hispánica en la Edad Antigua, Madrid, 1966, págs. 250, 253-54, 256, 271-72, 432, 445, 470, 493; L. VILLARONGA, Numismática antigua de Hispania, Barcelona, 1979 , págs. $283,285,295$; también y más recientemente véase, M. Gomis Justo, «Las monedas de Erkauika/Ercavica", Ciudades romanas..., op. cit., págs. 294-308.

72 Vid., A. Rodriguez Colmenero, "Cuenca romana...", art. cit., pág. 231, n. 80; también L.A. CuRchin, The local magistrates of Roman Spain, Toronto, 1990, pág. 208; AE, 1985, n. ${ }^{\circ} 615$

73 Además de la inscripción de nota anterior, véase también CIL, II, 3165a; J. VIVES, Inscripciones latinas..., op. cit., pág. 205, n. ${ }^{\circ}$ 1758; M. Osuna RuIz, Arqueología Conquense, Ercavica l. Aportación al estudio de la romanización de la Meseta, Cuenca, 1976, págs. 25-26.

74 Vid., M. Osuna Ruiz, Arqueología Conquense, Ercavica 1..., op. cit., págs. 19-25.

75 M. Osuna Ruiz, "Avance de las excavaciones en Ercavica (Cañaveruelas, Cuenca)", XIII CNA, (Huelva, 1973), Zaragoza, 1975, págs. 623-626; Id., Arqueología Conquense, Ercavica l..., op. cit:; Id., "Avance de las excavaciones de Valeria y Ercavica. Campañas 1974-75", XIV CNA, (Vitoria, 1975), Zaragoza, 1977, págs. 1129-1132; Id., NAHArq., 5, 1977, págs. 23-28; Id., "Diez años de excavaciones arqueológicas en Ercavica (Cañaveruelas, Cuenca)". Homenaje al Prof. Martín Almagro Basch, T. Ill, Madrid, 1983, págs. 263-274; M. Osuna Rulz, "Ercavica", Ciudades

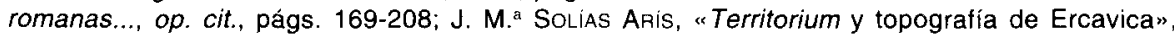
Ciudades romanas..., op. cit., págs. 209-238; R. Barroso Cabrera, J. Morín DE Pablos, "El edificio de baños de Ercavica". Ciudades romanas..., op. cit., págs. 239-288; M. Gomis Juste, "Las monedas de Erkauika/Ercavica", Ciudades romanas..., op. cit., págs. 289-345. 
Pero junto a esta serie de municipios, cabe mencionar también en este ámbito territorial, otros núcleos que es probable llegasen a alcanzar estatuto privilegiado.

Éste es el caso de Sisapo citado ya en Plinio ${ }^{76}$ entre los oppida non ignobilia del conventus Cordubensis (N.h., III, 14: Altera Baeturia, quam diximus Turdulorum et conventus Cordubensis habet oppida non ignobilia.. Sisaponem), y cuya importancia como centro minero ${ }^{77}$, posibilitaría su promoción jurídica, efectuada según G. Alföldy ${ }^{78}$ quizá a comienzos de época imperial.

También status privilegiado puede pensarse para Mentesa Oretanorum ${ }^{79}$ aun cuando es mencionada por Plinio (III, 25) como estipendiaria, llegando a ser en época tardía sede episcopal. Igualmente Oretum, uno de los principales enclaves del territorio oretano septentrional ${ }^{80}$, es citado por Plinio

76 Sisapo es mencionado por Plinio (III, 14) entre los núcleos de la Beturia túrdula, sin embargo en Ptolomeo (II, 6, 58: $\Sigma l \sigma \alpha \pi \omega v \eta)$ se incluye en la Citerior, lo cual podría explicarse según R. ThOUVENOt por la rectificación de límites provinciales que debió efectuarse ya avanzado el siglo I, vid., Essai sur la province romaine de Betique, París, 1940, págs. 164-165 y 248; véase también sobre dicha cuestión, A. ALBERTINI, Les divisions administratives de l'Espagne romaine, París, 1923, págs. 35 y 114-115; L. GARCIA IGLESIAS, "La Beturia, un problema geográfico de la Hispania Antigua", AEArq., 44, 1971, págs. 102-3; A. Prieto ARCINIEGA, Estructura social del Conventus Cordubensis durante el Alto Imperio Romano, Granada, 1973, pág. 134; N. Marin Díaz y A. Prieto ARCINIEGA, «En torno a un nuevo planteamiento de los límites de la provincia romana de la Bética», HAnt., 4, 1974, pág. 82; J.M. ROLDÁN HERVÁs, «La organización político-administrativa y judicial de la Hispania romana", $H .{ }^{a}$ de España de R. Menéndez Pidal, II, 2, Madrid, 1982, pág. 100.

77 Vid., G. Carrasco Serrano, "Núcleos de población romanos...", art. cit., págs. 310-313 sobre el yacimiento de La Bienvenida donde se viene ubicando últimamente Sisapo, vid., C. FERNÁNDEZ OCHOA ET ALI, Sisapo I. Excavaciones arqueológicas en La Bienvenida, Almodóvar del Campo (Ciudad Reai), Toledo, 1994.

78 G. AlFÖLDY, Römisches Städtewesen..., op. cit., pág. 56; en el mismo sentido J.M. ABASCAL, U. ESPINOSA, La ciudad hispano-romana..., op. cit., pág. 66, fig. 8. Sin embargo sobre las reservas de A.U. STYLow al respecto, teniendo en cuenta la mayoría de municipios flavios de la zona, vid., “El municipium flavium $V(-)$ de Azuaga (Badajoz) y la municipalización de la Baeturia Turdulorum», SHHA, IX, 1991, págs. 11-27.

79 Véase G. Alföloy, Römisches Städtewesen..., op. cit., págs. 37-41; J.M. AbASCAL, U ESPINOSA, La ciudad hispano-romana..., op. cit., pág. 66, fig. 8.

Bo Aunque ni las fuentes griegas ni latinas permiten precisar con total exactitud su localización, tradicionalmente se viene ubicando en torno a Nuestra Señora de Zuqueca o de Oreto, que conserva el antiguo nombre, junto al río Javalón en el término municipal de Granátula de Calatrava, cf., AmBrosio de Morales, Las Antigüedades de las ciudades de España, Alcalá de Henares, MDLXXV, págs. 75-76; E. FloREZ, España Sagrada, VII, pág. 263 ss.; J.A. CEAN Bermùdez, Sumario de las antigüedades..., op. cit., págs. 102-103; M. CoRTÉS y LóPEz, Diccionario geográfico-histórico de la España Antigua, T. III, Madrid, 1836, págs. 255-256; E. SAavedRA, Discursos leidos ante la Real Academia de la Historia, Madrid, 1862, pág. 99; E. HüBnER, C/L, II, pág. 431; I. HeRVÁS Y BuendiA, Diccionario histórico-geográfico de la provincia de Ciudad Real, Ciudad Real, 1914, 3. ${ }^{\circ}$ ed., págs. 491 ss.; K. MILler, Itineraria Romana. Römische Reisewege an der Hand der Tabula Peutingeriana, Stuttgart, 1916, col. 159. Igualmente, A. SCHULTEN, RE, XVIII, 1, 1942, col. 1019; Id., FHA, VI, pág. 201; A. Garcia BELlido, La España del siglo primero de 
entre los estipendiarios del conventus Carthaginensis (III, 25): stipendiariorum autem celeberrimi...), sin embargo es muy posible llegase a alcanzar condición privilegiada ${ }^{81}$, con anterioridad incluso a época flavia.

Recientemente en el importante enclave del Tolmo de Minateda (provincia de Albacete), la evidencia desde el punto de vista epigráfico de duoviri (T(itus) Martiu[s--]/V(ibius) Fulvius Quetu[s]/G(aius) Grattius Grattianu[s]/II viri $H\left(\right.$ oc) $O$ (pus) $F$ (aciendum) $C$ (uraverunt) ${ }^{82}$, ha permitido proponer la existencia de un nuevo municipio ${ }^{83}$ en este área objeto de estudio. Con una amplia ocupación cronológica ${ }^{84}$ constatable ya desde la Edad del Bronce, el Tolmo de Minateda estaría en relación con las vías de comunicación de su entorno ${ }^{85}$, y sobre todo con la ruta que unía Carthago Nova con el interior meseteño atestiguada a través de diversos miliarios.

nuestra era, Madrid, 1947, pág. 238; M. CORCHADO SORIANO, «Estudio sobre vías romanas entre el Tajo y el Guadalquivir", AEArq., 42, 1969, pág. 154; Id., Estudio del Campo de Calatrava III. Los pueblos y sus términos, Ciudad Real, 1982, págs. 260 ss.; sobre las excavaciones efectuadas en el Cerro Domínguez, vid., G. Nieto ET ALII, Oreto I, Madrid, 1980.

81 Vid., G. Alföldy, Römisches Städtewesen..., op. cit., pág. 52; J.M. ABASCAL, U. EsPINOSA, La ciudad hispano-romana..., op. cit., pág. 66, fig. 8; J.C. Olivares PedReño, Conflicto político y promoción juridica..., op. cit., pág. 222, nota 500 .

82 L. Abad CASal, "La epigrafía del Tolmo de Minateda (Hellín, Albacete) y un nuevo municipio romano del conventus Carthaginensis", AEArq., 69, 1996, pág. 81.

83 Vid., L. ABAD CASAL ET ALII, «El proyecto de investigación arqueológica Tolmo de Minateda (Hellin, Albacete): nuevas perspectivas en el panorama arqueológico del Sureste peninsular", Jornadas de Arqueología Albacetense en la Univ. Autónoma de Madrid, 1993, págs. 152-156; L. ABAD CASAL, "Algunas novedades onomásticas de la ciudad de llunum (El Tolmo de Minateda, Hellin, Albacete)", Antigüedad y Cristianismo, X, 1993, págs. 133-138; Id., "La epigrafía del Tolmo de Minateda...", art. cit., págs. 77-108. Por otra parte cabe resaltar que los nombres atestiguados de los duunviros, presentan una marcada vinculación con ámbitos levantinos, lo que ha hecho suponer la importancia que en la municipalización de este núcleo, ejercería la existencia de unas minorias relacionadas con poblaciones del Levante; también los Grattii se atestiguan desempeñando funciones en Valeria y Segobriga, véase al respecto J.M. ABASCAL, "Derecho latino y municipalización en Levante y Cataluña". Teoria y práctica del ordenamiento municipal en Hispania, Vitoria, 1996, págs. 277-278.

84 L. ABAD CASAL ET ALII, El Tolmo de Minateda. Una historia de tres mil quinientos años, Toledo, 1998.

${ }_{65}$ Véase, P. SILLIÉRES, "Una grande route romaine menant à Carthagène: la voie Saltigi-Carthago Nova», MDAI $(M), 23,1982$, págs. 247-257; F.J. JORDÁN MONTES ET ALII, “El poblamiento romano en el valle de Minateda-Agramón", Congreso de $H^{a}$ de Albacete, T. I, Albacete, 1984, págs. 217-218; A. SELVA INIESTA, J.F. JORDAN MONTES, "Notas sobre la red viaria romana en la comarca de Hellín-Tobarra (Albacete)», Vías romanas del Sureste, Murcia, 1988, págs. 85-99; P. SiLliĖRES, Les voies de communication de l'Hispanie meridionale, París, 1990, págs. 384 ss.; J.L. LOPEZ PrEcioso, "Vías romanas y visigodas del Campo de Hellin", Antigüedad y Cristianismo, X, 1993, págs. 99-131. En cuanto al nombre de la ciudad. P. SILLIĖRES ha propuesto situar la Ilunum citada por Ptolomeo (II, 6, 60) y la lyyu(h) de Al-'Udrī en este emplazamiento del Tolmo de Minateda, vid., Les voies de communication..., op. cit., pág. 389: “Aussi préférons-nous situer llunum et lyyuh au Tolmo de Minateda: cet extraordinaire piton rocheaux se dresse en effet au milieu de la vallée de la Rambla de Tobarra, c'est-à-dire exactament sur le tracé de la route antique. En outre, il a fourni de nombreux temoignages d'une longue occupation qui s'y est maintenue depuis le milieu du premier millénaire avant Jésus-Christ 
A estos núcleos hay que añadir asimismo el testimonio de una $r(e s)$ $p$ (ublica) Edebensium ${ }^{86}$ en la localidad de Torrenueva ${ }^{87}$ en la provincia de Ciudad Real, que ha posibilitado plantear la existencia de una comunidad privilegiada ${ }^{88}$ más en este ámbito castellano-manchego ${ }^{89}$, área geográfica ésta en la que los sucesivos hallazgos epigráficos y arqueológicos permitirán ir conociendo cada vez mejor su proceso de municipalización.

jusqu'au Bas Empire et même jusqu'au début de l'occupation musulmane". En este mismo sentido y más recientemente cf., L. ABAD CASAL ET ALII, “El proyecto de investigación...", art. cit., pág. 156; L. ABAD CASAL, C. ARANEGUI GASCO, "Las ciudades romanas de los ámbitos levantino y baleárico", La ciudad hispanorromana, Barcelona, 1993, pág. 104; L. ABAD CASAL, "Algunas novedades onomásticas...", art. cit., pág. 135; Id., "La epigrafía del Tolmo de Minateda...", art. cit., pág. 97; L. ABAD CASAL, S. GutiérRez LloRET, «lyih (El tolmo de Minateda, Hellin, Albacete). Una civitas en el limes visigodobizantino", Antigüedad y Cristianismo, XIV, 1997, p. 598.

${ }^{86}$ Dicha referencia procede de un pondus con la siguiente inscripción: Imp(eratoris) Caes(aris) Traiani/Hadriani Aug(usti)/r(es) p(ublica) Edebensium/p(ondo) X. Por su parte F. FITA, BRAH, LXX, 1917, pág. 250 proporciona esta lectura: [EX a(uctoritate)] Imp(eratoris) Caes(aris) Traiani Hadriani Aug(usti) R(es) $p$ (ublica) Edebensium pondo $X$.

87 Según E. VASCO Y GALLEGO el lugar del hallazgo se produjo a 1 kilómetro de Torrenueva, vid., "Edeba, ciudad oretana", BRAH, LIV, 1909, págs. 485-488; también véase BRAH, LIII, 1908, pág. 436; F. FITA, BRAH, LXX, 1917, pág. 250; M. CORCHADO SORIANO, "Estudio sobre vías romanas...", art. cit., págs. 151 y 156; Id., Avance de un estudio..., op. cit., pág. 176; A. Tovar, Iberische Landeskunde..., op. cit., vol. III, pág. 183.

${ }_{88}$ Vid., G. AlfoldoY, Römisches Städtewesen..., op. cit., págs. 45-46; J.M. ABASCAL, U. EspinosA, La ciudad hispano-romana..., op. cit., pág. 66, fig. 8.

${ }_{89}$ También se ha sugerido la existencia de un núcleo de condición privilegiada según puede deducirse de la mención de una curia en un epigrafe de los alrededores de Elche de la Sierra en la provincia de Albacete, vid., J.M. ABASCAL PALAZÓN, Inscripciones romanas de la provincia de Albacete, Albacete, 1990, págs. 74-75 y 104. De interés resulta igualmente la inscripción procedente de la localidad de Almedina en la provincia de Ciudad Real, recogida por E. HüBNER, CIL, II, 3236 , en la que se hace referencia a la fórmula d(ecreto) d(ecurionum), vid., G. ALfOLdY, Römisches Städtewesen..., op. cit., págs. 41-45; J.M. ABASCAL, U. EsPINOSA, La ciudad hispano-romana.., op. cit., pág. 66, fig. 8 . 


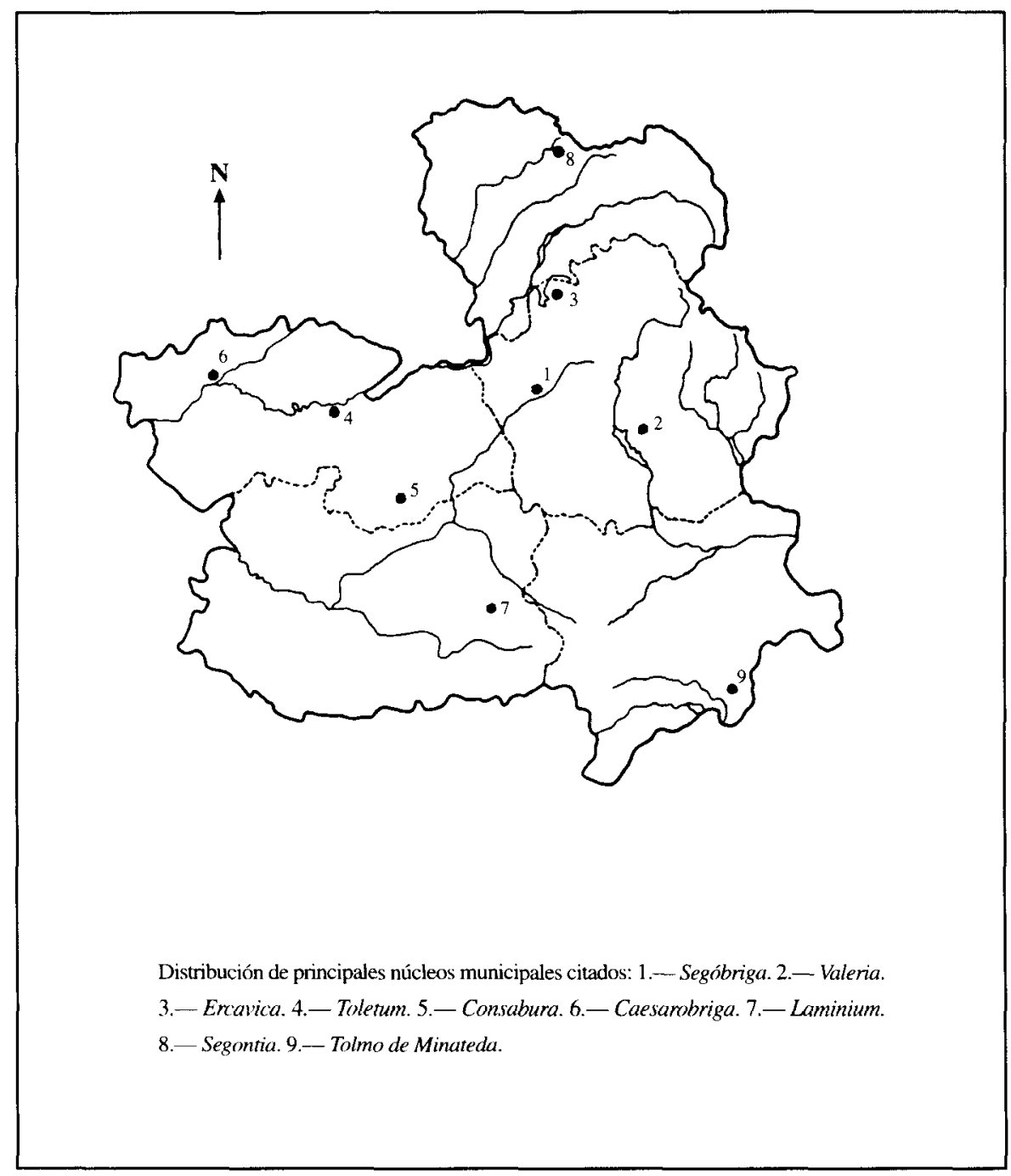

